\title{
Improvements to mechanical direct seeder design guided by the optimal sowing depth of soft spinifex (Triodia pungens)
}

\author{
M Masarei The University of Western Australia, Australia \\ AL Guzzomi The University of Western Australia, Australia \\ DJ Merritt Department of Biodiversity, Conservation and Attractions, Australia \\ TE Erickson The University of Western Australia, Australia
}

\begin{abstract}
The ability to reliably and efficiently restore degraded ecosystems at scale is a major challenge. Restoration on a mine site typically consists of either the planting of cultivated nursery stock or the direct seeding of seed onto site to reinstate native plants and ecosystems. At scale, planting seedlings can be extremely costly and time consuming and therefore, restoration practitioners have moved towards mechanical direct seeding methods. In many circumstances, however, mechanical direct seeding is unreliable and most mechanisms lack the versatility needed to plant a variety of native species in a range of sowing environments. Results of a global survey of restoration practitioners uncovered that seeding depth precision and accuracy is extremely important when distributing many native seeds. In order to guide improvements to the design of native seeders that are used in the Pilbara region of Western Australia, we studied the maximum and optimal emergence depth of a species crucial to restoration in the region, Triodia pungens (soft spinifex). Results showed that the current practice of broadcasting seeds on the soil surface may be inadequate to facilitate germination, and that covering seeds to $5 \mathrm{~mm}$ yields optimal emergence. Seedling emergence dropped off considerably at $10 \mathrm{~mm}$ with almost no emergence occurring once seeds were sown to $30 \mathrm{~mm}$. Most mechanical seeders currently in operation are unable to control depth to this level of precision, particularly on the rocky and uneven terrain associated with mine waste dumps. Future designs should focus on improving depth control in such conditions.
\end{abstract}

Keywords: restoration, direct seeding, mechanical seeders, Triodia pungens

\section{Introduction}

Rehabilitating ecosystems that have been disturbed by mining operations present a significant challenge to the mining industry, particular in dryland ecosystems. Despite significant investments by mining companies and the restoration ecology community, success rates in rehabilitating degraded sites remain low (Environmental Protection Authority 2014; James \& Carrick 2016). The inability to efficiently facilitate plant development highlights ecological and practical complexities that need to be overcome in order to optimise the process of rehabilitating degraded ecosystems (Miller et al. 2017; Shackelford et al. 2018). Amongst these factors, the process of handling and distributing seeds or seedlings into the environment is critical.

Typically, the reintroduction of plants for mine site restoration involves either the distribution of seeds directly to site, known as direct seeding, or the planting of seedlings that have been cultivated in a nursery (Masarei et al. 2019). However, both methods have their short-comings. For instance, the costly nature of cultivating seedlings in a nursery, as well as a much larger time needed to plant seedlings when compared to sowing seeds, makes tube stock plantings undesirable for large-scale restoration efforts (Palmerlee \& Young 2010; Cole et al. 2011). Sowing seeds directly to site with the aid of machinery is the most feasible method of establishing plants at large scales and therefore advances to seeding mechanisms are critical to advancing mine site restoration. 
To identify avenues to improve direct seeding methods and therefore, improve our ability to restore degraded ecosystems, Masarei et al. (2019) conducted a survey of restoration practitioners across the globe. It was identified that the ability for seeding machinery to precisely locate seeds to a desired depth was a significant limitation to direct seeding mechanisms currently in use and therefore, should form a focus of ecologists and engineers in the field of restoration.

It is well established that a viable, non-dormant seed needs to be located within the soil matrix at a location which provides adequate moisture, oxygen, light, and temperature to facilitate germination (Fenner \& Thompson 2005). The optimal temperature and water potential for germination is a point of focus for the restoration ecology community and therefore, for some species has been discussed in the literature (Lewandrowski et al. 2018). However, the location within the soil matrix that is most likely to provide optimal soil moisture and temperature is difficult to predict since they vary spatially and temporally through the soil profile. Most importantly, soil moisture and temperature vary significantly in the vertical direction (Richards 1949) and therefore, the depth at which a seed is sown is crucial to optimise germination. Emergence, the second life stage critical to establishing a mature plant, is also affected by the depth a seed is sown. Seeds must be covered deep enough to reduce the risk of predation, desiccation, and wind blowing seed offsite (Carrick \& Krüger 2007; DeFalco et al. 2012) but must not be sown too deep, otherwise the seed will contain insufficient internal energy to emerge (Daws et al. 2007). Practically, varying the soil moisture and temperature within the soil profile at scale is infeasible and hence, the placement of seeds at a particular depth is crucial to optimise germination, emergence, and establishment of plants.

In an attempt to quantify the constraints that internal energy stores impose on the maximum emergence depth of a particular species, Bond et al. (1999) developed an allometric relationship for the maximum shoot length that a seed of given mass can produce. They assume the volume of a seed must be conserved during the development of the seedling until it emerges and is able to photosynthesise and thus, maximum emergence depth scales with the cubed root of seed mass. Although this assumption is not strictly correct, as the cells within a seedling expand due to water uptake, their equation has been shown to be a good fit for the maximum emergence depth of 17 native South African arid zone species.

Although we can estimate the upper limits of emergence depth for a given species or seed, our ability to precisely position at a target depth is limited, particularly at shallow depths. Variation in seeding depth caused by dynamic excitation can affect the precision of a seeding mechanism significantly. A study of the dynamic performance of a precision agricultural seeding machine operating over stubble showed that variation in seeding depth was distributed with Weibull distribution and a standard deviation of $8.7 \mathrm{~mm}$ when sown to a target depth $40 \mathrm{~mm}$ (Sharipov et al. 2017b; Sharipov et al. 2018). In mining environments such as those seen in the Pilbara region of Western Australia, when operating over rough, rocky soils, the amplitude of excitation could exceed that of stubbled soils increasing the variation in sowing depth. It is therefore important to quantify how variations in seeding depth and the upper limits of emergence depth for a particular species contribute to the percentage of seeds which successfully emerge when sowing seeds.

This paper attempts to quantify the biological and mechanical factors that contribute to the optimal depth placement of seeds by leveraging the work of other authors. Thus, we aim to gain a sense of the scale of improvement which needs to be made to existing seeding technologies to improve seeding efficiencies and therefore, improve restoration outcomes.

We use the equation for maximum emergence depth presented by Bond et al. (1999) to model the maximum emergence depth of native seeds critical to restoration in the Pilbara. We compare the distribution of native seed masses with that of agricultural species commonly sown in Western Australia for which suitable seeding machinery exists. We then use the data presented in Sharipov et al. (2017b) to estimate the magnitude of depth variation which would be expected when sowing native seeds using a traditional agricultural style device and the implication this has on the efficiency of seed use. Lastly, we discuss the effects that rocky soils, characteristic of the Pilbara region, may play in limiting emergence from depth and discuss results from an experiment aimed at determining the optimal sowing depth of Triodia pungens (soft spinifex); a species critical to mine site restoration in the Pilbara. 


\section{$2 \quad$ Methods}

\subsection{Maximum emergence depth}

To gain a sense of the range of maximum emergence depths that exist for species native to the arid Pilbara region of Western Australia the model presented in Bond et al. (1999) was used to calculate maximum emergence depths using the mean seed masses of 103 native Pilbara species (Erickson et al. 2016). Bond et al. (1999) assumed that maximum emergence depth scales with the cubed root of seed mass as given in Equation 1:

$$
d_{\max }=c \times m^{\frac{1}{3}}
$$

where:

$$
\begin{aligned}
& \mathrm{c}=\text { a constant } \\
& \mathrm{m}=\text { mass of a given seed }(\mathrm{mg}) \\
& d_{\text {max }}=\text { maximum emergence depth }(\mathrm{mm})
\end{aligned}
$$

Fitting a curve to data from 17 native South African arid zone species, including taxa from families also occurring in the Pilbara, Bond et al. (1999) found the constant, c, to be 27.3. Therefore, we assume that the Bond et al. (1999) model provides a good estimate for maximum emergence depth of species in the Pilbara. The sample of 103 species, covers 52 commonly occurring genera in the Pilbara and is therefore, a good representation of the size of seeds of Pilbara species as a whole. Critically, genera which make up the majority of biomass in Pilbara plant communities-Triodia, Acacia, and Eucalyptus-are well represented making the sample a good representation of species critical to mine restoration in the region.

\subsection{Mechanism dynamic performance}

To estimate the effect of machine imprecision on the percentage of seeds sown that emerge, the standard deviation in sowing depth of approximately $8.7 \mathrm{~mm}$ found in Sharipov et al. (2018) for a target sowing depth of $40 \mathrm{~mm}$ is used to model the chance of emergence. The number of seeds sown which are expected to sit below the maximum emergence depth predicted by the Bond et al. (1999) equation is determined by comparing the distribution of seeding depths, at a given target seeding depth, to the seed's estimated maximum emergence depth. It is assumed that variation in seeding depth is distributed normally and remains constant with changes in target seeding depth. This is because the vertical component of dynamic excitation of the seeding mechanism largely results from the roughness of the soil and speed of travel which, as a first approximation, are considered independent of the chosen target depth (Sharipov et al. 2017a).

\subsection{Influence of rocks}

Since the soil profile of the Pilbara region is characteristically rocky, a statistical model is developed which estimates the chance that a seed sown to a given depth sits below a rock and therefore, may be unable to emerge.

Consider a square rock of area, $a$, in the soil profile. The chance of a seedling being covered by this rock is

where:

$$
A=\text { total area of the soil section being considered }
$$

The chance of not being covered is thus

$$
1-\frac{a}{A}
$$


For $\mathrm{k}$ such rocks in the profile the chance of not being covered is therefore

$$
1-\left(\frac{A-a}{A}\right)^{k}
$$

and for $k_{i}$ rocks of area $a_{i}$ the formula extends to

$$
1-\prod_{i=0}^{n} \frac{\left(A-a_{i}\right)^{k_{i}}}{A^{k_{i}}}
$$

A characteristic sample of $5.95 \times 10^{-4} \mathrm{~m}^{3}$ of top soil from near the town of Newman in the Pilbara was taken and analysed using a sieve stack to test the particle size distribution of the sample. A mechanical shaker was used to separate the soil sample into discrete particle sizes. For this study any particle which failed to pass through a $6.7 \mathrm{~mm}$ (square mesh) or larger sieve was considered to be a rock with large enough mass that an emerging $T$. pungens seedling could not move and therefore, restrain the seedling from reaching the soil surface if encountered. Although rocks caught with a given mesh size had a minimum projected twodimensional area larger than that of the area of the holes in the mesh, to ensure a conservative estimate, it is assumed that rocks caught on a given sieve have area equal to that of the holes of the mesh. Rocks caught above a given sieve size were counted and then the total number of rocks expected in a $1 \mathrm{~m}^{3}$ volume of soil calculated by scaling the sample appropriately. This allowed the total number of rocks above a certain depth over a $1 \mathrm{~m}^{2}$ section to be calculated and therefore, the total fraction of area covered by rock for a seed placed at a given depth.

\subsection{Optimal sowing depth of Triodia pungens}

To determine the optimal sowing depth of a species critical to mine site restoration in the Pilbara, $T$. pungens (soft spinifex) seeds were sown into three replicated plots containing topsoil. Within each plot seeds were sown into rows of seven different depths $(0,5,10,15,20,30$, and $40 \mathrm{~mm})$ which were replicated twice within each plot. One hundred and fifty seeds were sown into each row with a lab-based germinability for the sample of $86 \%$. The plots were situated in an open air, purpose-built rain exclusion facility located at Mt Whaleback mine site near Newman, Western Australia (Figure 3). To ensure germination and emergence was not restricted by water availability, plots received a simulated rainfall event of $15 \mathrm{~mm}$ twice a day, every two days. Probes buried to about $20-30 \mathrm{~mm}$ monitored the water potential and temperature of the soil throughout the trial. The number of emerged seedlings was counted 20 days after the seeds had been sown.

\section{Results and discussion}

\subsection{Maximum emergence depth}

Figure 1 illustrates an estimate of the distribution of maximum emergence depths amongst seeds of species native to the Pilbara based on results from Equation 1. The smallest maximum emergence depth was $5.4 \mathrm{~mm}$ whilst the largest maximum emergence depth was $167 \mathrm{~mm}$ (Figure 1). The median maximum emergence depth was $37.5 \mathrm{~mm}$ and thus, it is predicted that $50 \%$ of species will not emerge if sown to $37.5 \mathrm{~mm}$ or deeper. Over $90 \%$ of species will fail to emerge if sown deeper than $87.5 \mathrm{~mm}$. It should also be noted that only species from a few genera produce seeds large enough to emerge from deeper than $50 \mathrm{~mm}$. Genera from the Fabaceae and Proteaceae families being prominent examples (Acacia, Senna, and Grevillea). In fact, $80 \%$ of all genera reported in Erickson et al. (2016) will not emerge if sown to $65 \mathrm{~mm}$ or deeper. In comparison to agricultural seeds, the seeds of native plants are small. For example, the four crop varieties that count for the largest portion of Western Australia's exports-wheat ( $\sim 40 \mathrm{mg})$, canola ( $\sim 4 \mathrm{mg})$, barley ( $\sim 5 \mathrm{mg})$, and lupins ( $\sim 160 \mathrm{mg}$ ) (Department of Primary Industries and Regional Development [DPIRD] 2019) -all have seeds much larger than the median mass of the native Pilbara species studied ( $2.6 \mathrm{mg}$ ). Even ryegrass, which is considered to be a particularly small seeded pasture species, has a mass of $\sim 3 \mathrm{mg}$ (Stanisavljević et al. 2017) which is larger than all the native grasses in this sample. Seeding mechanisms that are used in agriculture are often designed to sow seeds much deeper than what is required by native seeds which is reflected by the difference in distribution of seed mass between native and agricultural seeds. 

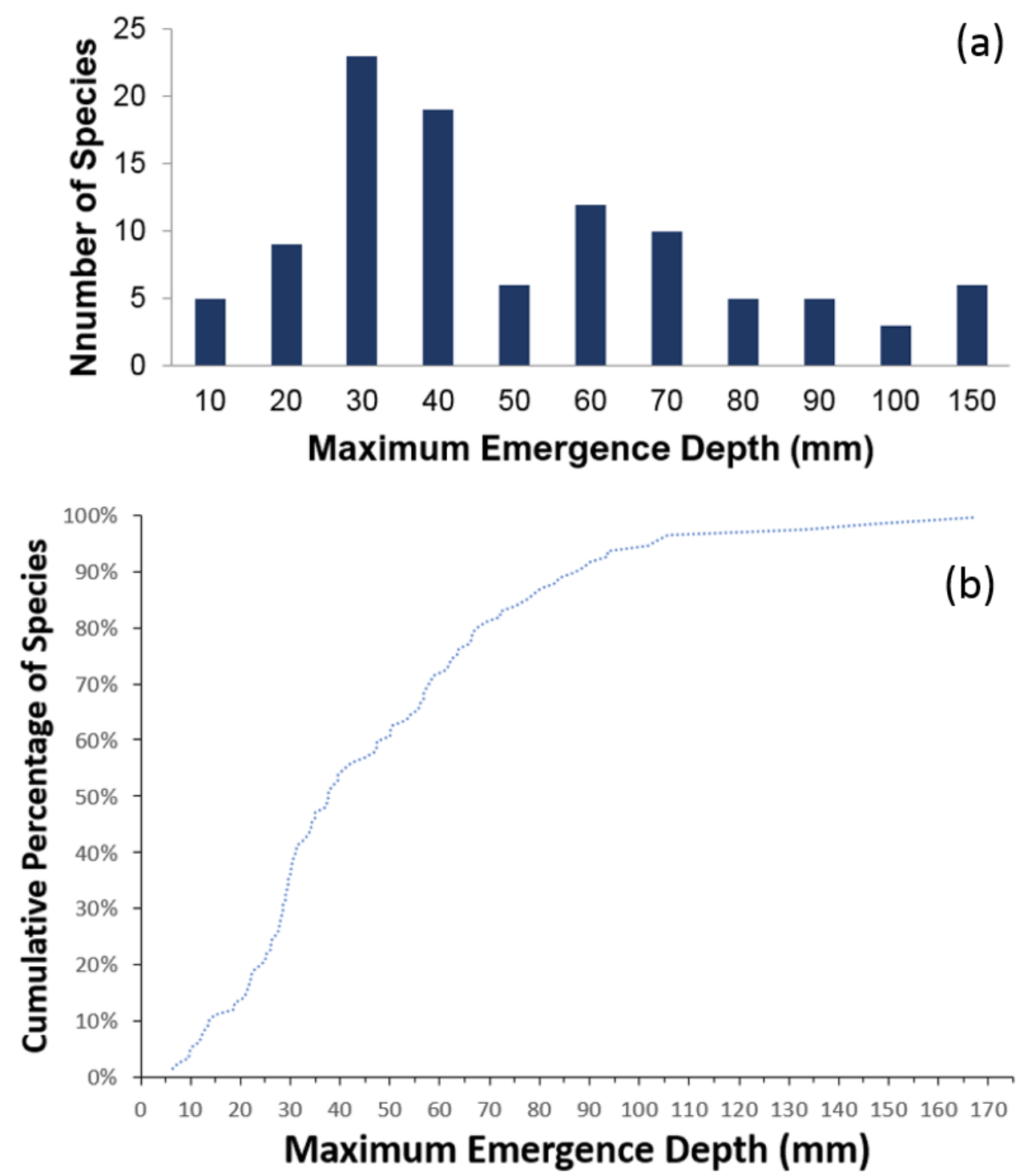

Figure 1 Prediction of maximum emergence depth for 103 Pilbara species using the Bond et al. (1999) model. (a) Histogram of maximum emergence depth; (b) Cumulative distribution of maximum emergence

\subsection{Mechanism dynamic performance}

Figure 2 illustrates the effect of seeding depth variation on emergence percentage for a standard deviation in seeding depth of $8.7 \mathrm{~mm}$, as was found in Sharipov et al. (2018), for a modern no-till drill. It can be seen that wheat seeds with an average mass of about $40 \mathrm{mg}$ and therefore, expected maximum emergence depth of about $90 \mathrm{~mm}$ using the Bond et al. equation, when sown in the target depth range of $20-50 \mathrm{~mm}$ (DPIRD 2019) will, despite variation in sowing depth, always be sown shallow enough to emerge (Figure 2). For T. pungens, with a mass of about $1.25 \mathrm{mg}$, seeds would need to be sown to a target depth of about $10 \mathrm{~mm}$ or lower to ensure that no seed is sown too deep to emerge. For even smaller native seeds with mass of $0.3 \mathrm{mg}$ or lower, variation in seeding depth with always result in some seeds being sown too deep to emerge. This corresponds to about $10 \%$ of all species. These species are therefore, incompatible with modern agricultural seeding devices. 


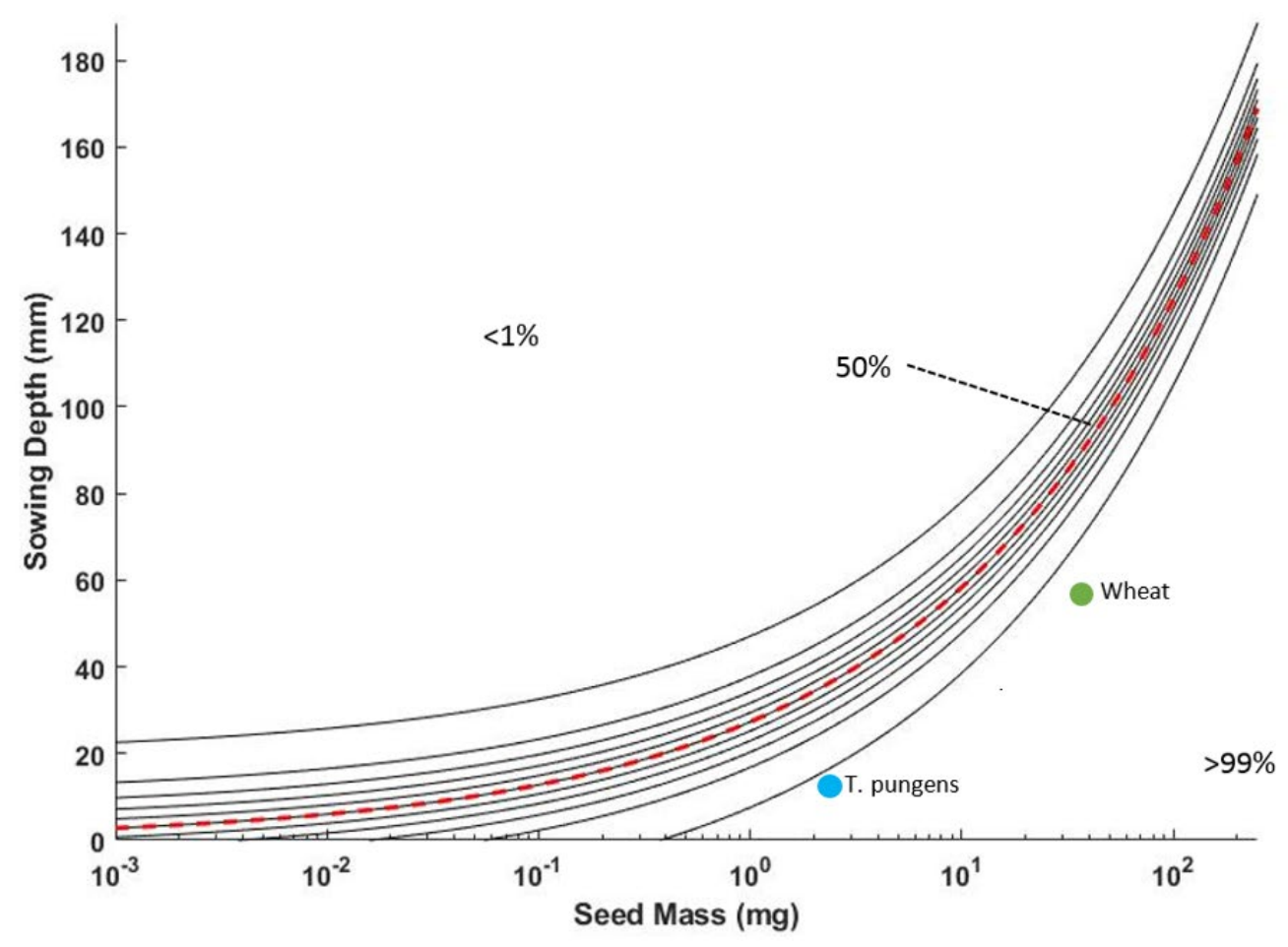

Figure 2 Plot indicating the optimal target sowing depth for a seed of given mass. Black lines indicate the proportion of seed that will be sown too deep to emerge for a given seed mass and are plotted at increments of $10 \%$. The red dotted line indicates the point at which $50 \%$ of seeds will be sown too deep to emerge and corresponds to the curve of maximum emergence depth for a given mass produced by the Bond et al. 1999 equation. As an example, the depth wheat is sown to in practice is shown with a green dot. The estimated optimal sowing depth of soft spinifex (Triodia pungens) is shown with a blue dot

\subsection{Influence of rocks}

Table 1 shows the particle size distribution of three topsoil samples typical of Pilbara soils. Summarised in Table 2 is the chance that a seedling buried to a given depth will be covered by a rock if sown into such a top soil according to Equation 5. It can be seen that burial of any seed to $50 \mathrm{~mm}$ in depth with result in greater than a $50 \%$ change that the seedling will encounter a rock on its path to the surface. It is unclear to what degree seedlings possess the ability to navigate obstacles in the soil profile however it has been shown that adding a layer of rock mulch to a reclamation site in an arid setting can lead to a marked reduction in plant cover (Fehmi 2018). If it is assumed that seedlings cannot navigate obstacles in the soil matrix at all, at a depth of $50 \mathrm{~mm}$ more than half of seeds will fail to emerge after encountering a rock in their path to the surface. If it assumed that seedlings possess the ability to navigate rocks in the soil, since emergence depth is limited by the shoot length which can be created, any deviation from vertical growth will reduce the maximum emergence depth of the seedling. For any sowing depth close to the maximum emergence depth this would result in a reduction the number of seedlings that can produce shoots long enough to emerge.

As an example, given the average mass of $1.25 \mathrm{mg}$ for a T. pungens seed (Erickson et al. 2016), the maximum emergence depth predicted by the Bond et al. 1999 model is about $30 \mathrm{~mm}$. However, if a seed were to be sown to $30 \mathrm{~mm}$ in Pilbara soils $37 \%$ of seedlings would encounter a rock (Table 2), thereby resulting in $37 \%$ loss of viable seed due to either seedlings encountering a rock and failing to grow past them, or seedlings being unable to produce a long enough shoot to reach the surface. This indicates that in practice and in the field, it is more likely that the effective maximum emergence depth for $T$. pungens, is much shallower than $30 \mathrm{~mm}$. Assuming conservatively that seedlings are unable to navigate rocks, seeding of a species of any size to $50 \mathrm{~mm}$, as is common for many agricultural crops, would result in greater than $50 \%$ of seeds failing to emerge. 
Table 1 Summary of a particle size distribution test from a sample of topsoil taken in the Pilbara

\begin{tabular}{|c|c|c|}
\hline \multicolumn{3}{|c|}{ Number of rocks in sample } \\
\hline Rock size (mm) & Area $\left(m^{2}\right)$ & Rocks per $1 \mathrm{~m}^{3}$ \\
\hline 50 & 0.00250 & 110 \\
\hline 37.5 & 0.00141 & 511 \\
\hline 26.5 & 0.00070 & 2,141 \\
\hline 19 & 0.00036 & 7,234 \\
\hline 13.2 & 0.00017 & 21,627 \\
\hline 6.7 & 0.00004 & 150,898 \\
\hline
\end{tabular}

Table 2 Number of rocks which are expected above the specified soil depth based on the number of rocks in the topsoil sample taken in the Pilbara. The chance that a seedling is covered by a rock for a given sowing depth, as calculated by Equation 5, is shown for this soil sample

\begin{tabular}{llllllll}
\hline Rock size $(\mathbf{m m})$ & $\begin{array}{l}\text { Depth } \\
\mathbf{5 m}\end{array}$ & $\mathbf{1 0} \mathbf{~} \mathbf{m m}$ & $\mathbf{1 5} \mathbf{~} \mathbf{m}$ & $\mathbf{2 0} \mathbf{~} \mathbf{m}$ & $\mathbf{3 0} \mathbf{~} \mathbf{m}$ & $\mathbf{4 0} \mathbf{~ m m}$ & $\mathbf{5 0} \mathbf{~ m}$ \\
\hline $\mathbf{5 0}$ & 1 & 1 & 2 & 2 & 3 & 4 & 5 \\
$\mathbf{3 7 . 5}$ & 3 & 5 & 8 & 10 & 15 & 20 & 26 \\
$\mathbf{2 6 . 5}$ & 11 & 21 & 32 & 43 & 64 & 86 & 107 \\
$\mathbf{1 9}$ & 36 & 72 & 109 & 145 & 217 & 289 & 362 \\
$\mathbf{1 3 . 2}$ & 108 & 216 & 324 & 433 & 649 & 865 & 1,081 \\
$\mathbf{6 . 7}$ & 754 & 1,509 & 2,263 & 3,018 & 4,527 & 6,036 & 7,545 \\
Chance of cover & $8 \%$ & $14 \%$ & $21 \%$ & $27 \%$ & $37 \%$ & $47 \%$ & $54 \%$ \\
\hline
\end{tabular}

\subsection{Optimal sowing depth of Triodia pungens}

Results of the experiment to determine the optimal sowing depth of $T$. pungens in Pilbara soils indicate that sowing seeds to $5 \mathrm{~mm}$ results in maximum emergence (Figure 3). Sowing seeds deeper than $5 \mathrm{~mm}$ resulted in lower emergence with a trend towards a reduction in emergence the deeper seeds were sown. At $30 \mathrm{~mm}$ and $40 \mathrm{~mm}$ almost all seeds sown failed to develop into emerged seedlings. However, a small number of seedlings did emerge at $40 \mathrm{~mm}$ despite being sown in rocky profiles. Assuming the Bond et al. 1999 model is correct, a seed would have to have a mass of $3 \mathrm{mg}$, which is greater than 2.5 times the size of an average T. pungens seed, to emerge from $40 \mathrm{~mm}$. As part of this study, a sub-sample of $100 \mathrm{~T}$. pungens seeds were weighed before being sown. The maximum mass for this sample was $1.98 \mathrm{mg}$, only $66 \%$ the size of the $3 \mathrm{mg}$ seed that would be needed if the Bond et al. (1999) model perfectly described Pilbara species. This discrepancy indicates that the Bond et al. (1999) model should be treated with caution when applied to native Pilbara species since it may underestimate the maximum emergence depth of some species. However, the results suggest that sowing much lower than the maximum emergence depth yields optimal emergence particularly in the rocky soils of the Pilbara.

A much lower optimal emergence depth than the maximum emergence depth indicates that the results are somewhat consistent with the hypothesis that the presence of rocks can limit emergence. Soil moisture and temperature probes buried to approximately $20-30 \mathrm{~mm}$ indicated that the temperature was held at an average temperature of $35^{\circ} \mathrm{C}$ and water potential of $-0.45 \mathrm{MPa}$, both of which are adequate for germination to occur (Lewandrowski et al. 2018). Soil moisture evaporates from the soil surface which suggests that seeds have better access to moisture the deeper they are indicating that a lack of water, and therefore germination 
was likely not the cause of reduced emergence for seed sown deeper than $10 \mathrm{~mm}$. The fact that emergence at depth was much lower than at shallow depths, even when the seedlings were sown to depths not predicted to limit emergence, suggests that some factor other than maximum tissue length is reducing emergence and could be due to presence of rocks in the soil profile.

The optimal sowing depth of $5 \mathrm{~mm}$ and drop off in emergence after $10 \mathrm{~mm}$ found in this study is consistent with the natural seed distribution of $T$. pungens in the wild (Wright \& Fensham 2016). It has been found that in a healthy spinifex grassland $75 \%$ of $T$. pungens seeds were located in the upper $5 \mathrm{~mm}$ of the soil and $98 \%$ of seeds were located in the upper $10 \mathrm{~mm}$ of soil. The precision level of agricultural devices such as the one described above are inadequate for the optimal placement of small native seeds such as $T$. pungens. Seeding precision would need to improve to be within $5 \mathrm{~mm}$ even over rocky soils, for species such as $T$. pungens, to ensure that seeds are kept below the surface and above $10 \mathrm{~mm}$ when sown to a target depth of $5 \mathrm{~mm}$, thereby maximising seed use efficiency.
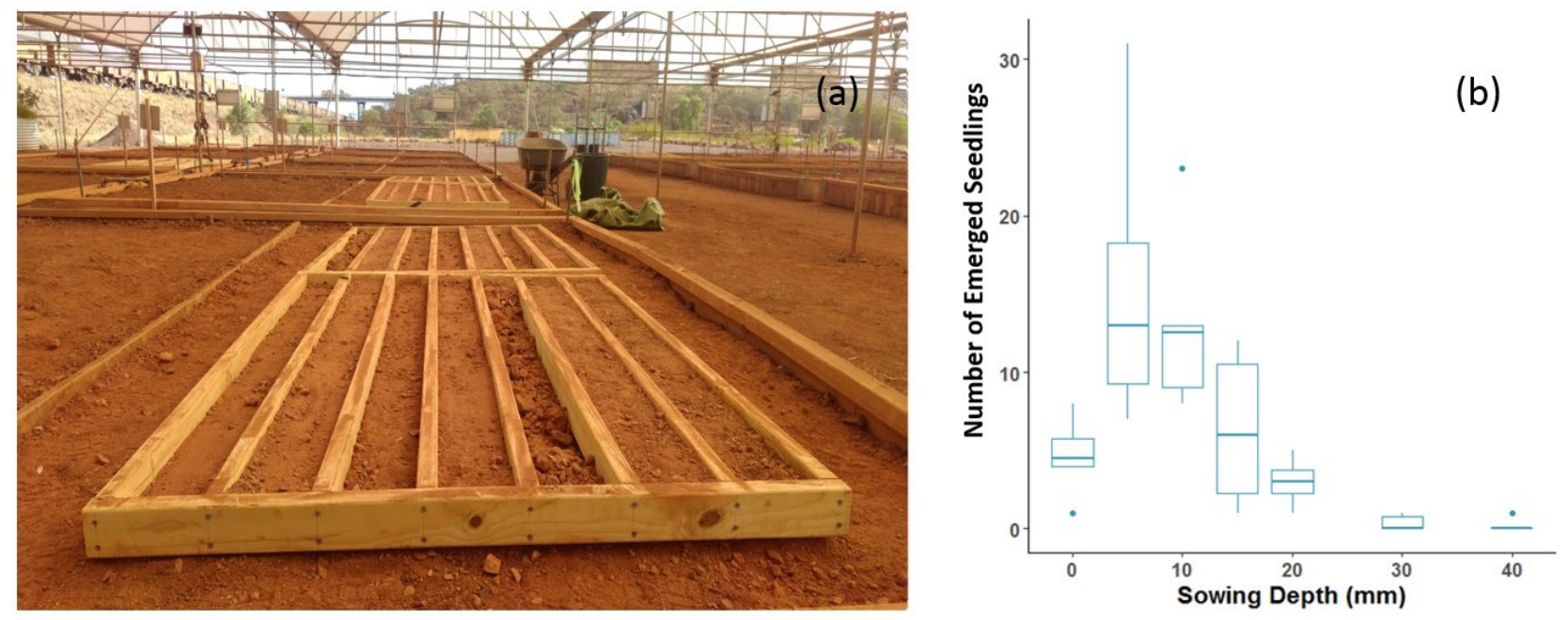

Figure 3 (a) Image showing the layout of plots into which Triodia pungens seeds were sown. Seeds were sown to seven different depths and replicated twice within each plot; (b) Box plot showing the distribution of emergence numbers for each sowing depth

\section{Conclusion}

The challenge of reinstating ecosystems after they have been degraded by mining operations requires engineering solutions that are guided by the ecological requirements of native seeds. Native seeds, on average, have much smaller seeds than those of agricultural crops and therefore work needs to be done to adapt current seeding technologies, or develop new solutions, to ensure seeds are placed at the optimal location within the soil profile. Although the precision of modern agricultural seeding devices suits agricultural seeds well, depth variation is too high for smaller native species of the Pilbara. Compounding the issue rocky soil profiles may, in effect, reduce the maximum emergence depths of seeds sown in such a profile increasing the need for higher depth precision. For T. pungens, a species critical to restoration in the Pilbara seeds were found to emerge at the highest efficiency when sown to $5 \mathrm{~mm}$ and no greater than $10 \mathrm{~mm}$ when sown in rocky Pilbara soils despite a predicted maximum emergence depth of $30 \mathrm{~mm}$.

This paper uses depth precision data for a single agricultural device as a tool to estimate the compatibility of native seeds with modern techniques, however infield experiments should be undertaken to confirm these predictions. As highlighted throughout this paper, more work needs to be done to understand how the limits of emergence depth are controlled in rocky soils if we are to improve our ability to facilitate the establishment of reproductively mature plants on mine sites. In particular the dynamic performance of seeding mechanisms is critical to optimising emergence and therefore establishment efficiency should be looked at in more detail. 


\section{Acknowledgement}

This research was conducted as part of the Global Innovation Linkages project grant (GIL53873) titled 'Eco-engineering solutions to improve mine site restoration outcomes' funded by the Department of Industry, Innovation and Science, and the Restoration Seedbank Initiative, a BHP Western Australia Iron Ore Community Development Project (contract no. 8600048550). Authors acknowledge funding by The University of Western Australia (UWA) Research Impact Grant 2018 'Catalysing the adoption of 'restoration engineering' in large-scale restoration programs'. Monte Masarei acknowledges the financial support provided through the Robert and Maude Gledden Postgraduate Research Scholarship administered by UWA.

\section{References}

Bond, WJ, Honig, M \& Maze, KE 1999, 'Seed size and seedling emergence: an allometric relationship and some ecological implications', Oecologia, vol. 120, pp. 132-136.

Carrick, PJ \& Krüger, R 2007, 'Restoring degraded landscapes in lowland Namaqualand: Lessons from the mining experience and from regional ecological dynamics', Journal of Arid Environments, vol. 70, pp. 767-781.

Cole, RJ, Holl, KD, Keene, CL \& Zahawi, RA 2011, 'Direct seeding of late-successional trees to restore tropical montane forest', Forest Ecology and Management, vol. 261, pp. 1590-1597.

Daws, MI, Ballard, C, Mullins, CE, Garwood, NC, Murray, B, Pearson, TRH \& Burslem, DFRP 2007, 'Allometric relationships between seed mass and seedling characteristics reveal trade-offs for neotropical gap-dependent species', Oecologia, vol. 154, pp. 445-454.

DeFalco, LA, Esque, TC, Nicklas, MB \& Kane, JM 2012, 'Supplementing seed banks to rehabilitate disturbed Mojave Desert shrublands: Where do all the seeds go?', Restoration Ecology, vol. 20, pp. 85-94.

Department of Primary Industries and Regional Development 2019, Crops, Government of Western Australia, viewed April 2019, https://www.agric.wa.gov.au/crops

Environmental Protection Authority 2014, Cumulative environmental impacts of development in the Pilbara region: Advice of the Environmental Protection Authority to the Minister for Environment under Section 16(e) of the Environmental Protection Act 1986, Government of Western Australia.

Erickson, T, Barrett, R, Merritt, D \& Dixon, K 2016, Pilbara seed atlas and field guide: plant restoration in Australia's arid northwest, CSIRO Publishing, Victoria.

Fehmi, JS 2018, 'Research note: A rock mulch layer supported little vegetation in an arid reclamation setting', Arid Land Research and Management, vol. 32, pp. 253-256.

Fenner, M \& Thompson, K 2005, The ecology of seeds, Cambridge University Press, Cambridge.

James, JJ \& Carrick, PJ 2016, 'Toward quantitative dryland restoration models', Restoration Ecology, vol. 24, pp. S85-S90.

Lewandrowski, W, Erickson, TE, Dalziell, EL \& Stevens, JC 2018, 'Ecological niche and bet-hedging strategies for Triodia (R.Br.) seed germination', Annals of Botany, vol. 121, pp. 367-375.

Masarei, M, Guzzomi, AL, Merritt, DJ \& Erickson, TE 2019, 'Factoring Restoration Practitioner Perceptions into Future Design of Mechanical Direct Seeders', Restoration Ecology, unpublished.

Miller, BP, Sinclair, EA, Menz, MHM, Elliott, CP, Bunn, E, Commander, LE...Stevens, JC 2017, 'A framework for the practical science necessary to restore sustainable, resilient, and biodiverse ecosystems', Restoration Ecology, vol. 25, pp. 605-617.

Palmerlee, AP \& Young, TP 2010, 'Direct seeding is more cost effective than container stock across ten woody species in California', Native Plants Journal, vol. 11, pp. 89-102.

Richards, LA 1949, 'Methods of measuring soil moisture tension', Soil Science, vol. 68, p. 95.

Shackelford, N, Miller, BP \& Erickson, TE 2018, 'Restoration of Open-Cut Mining in Semi-Arid Systems: A Synthesis of Long-Term Monitoring Data and Implications for Management', Land Degradation \& Development, vol. 29, pp. 994-1004.

Sharipov, GM, Paraforos, DS \& Griepentrog, HW 2017a, 'Modelling and simulation of the dynamic performance of a no-till seeding assembly with a semi-active damper', Computers and Electronics in Agriculture, vol. 139, pp. 187-197.

Sharipov, GM, Paraforos, DS \& Griepentrog, HW 2018, 'Implementation of a magnetorheological damper on a no-till seeding assembly for optimising seeding depth', Computers and Electronics in Agriculture, vol. 150, pp. 465-475.

Sharipov, GM, Paraforos, DS, Pulatov, AS \& Griepentrog, HW 2017b, 'Dynamic performance of a no-till seeding assembly', Biosystems Engineering, vol. 158, pp. 64-75.

Stanisavljević, R, Milenković, J, Štrbanović, R, Poštić, D, Velijević, N, Jovanović, S \& Tabaković, M 2017, 'Variability of Italian ryegrass and perennial ryegrass seed quality produced in two different regions', Journal on Processing and Energy in Agriculture, vol. 21, pp. 124-126.

Wright, BR \& Fensham, RJ 2016, 'Relationships between fire severity and recruitment in arid grassland dominated by the obligateseeding soft spinifex (Triodia pungens)', International Journal of Wildland Fire, vol. 25, pp. 1264-1272. 
